\title{
SOBRE LA EPÍSTOLA DE TERRAZAS PUES SIEMPRE TAN SIN CAUSA PRETENDISTE
}

\author{
Luis Ínigo-Madrigal \\ Universidad de Ginebra
}

\author{
Para Cedomil Goic. \\ Toto pectore.
}

\section{RESUMEN / ABSTRACT}

Entre los escasos poemas de Francisco de Terrazas que han llegado hasta nosotros se cuenta una epístola. La epístola es un género cultivado "desde los orígenes de la civilización mediterránea" y a lo largo de los siglos su práctica y su retórica han sufrido cambios, aunque hayan permanecido inmutables en su esencia. La Epístola de Terrazas acoge y vulnera esa tradición. A partir de un motivo con origen en la poesía trovadoresca y el dolce stil novo, muestra un entero conocimiento del género epistolar; el dominio de su retórica; la imitación de diversos poemas latinos. Pero a todo ello agrega elementos novedosos, de los cuales no es el menor la recurrencia a un motivo propio de la lírica popular hispánica. El artículo analiza el poema de Terrazas, cuya transcripción del original incluye, poniendo de manifiesto tanto sus fuentes clásicas cuanto los elementos innovadores incluidos por el poeta mexicano.

Palabras Clave: Francisco de Terrazas, poesía colonial, epístola, tradición clásica, romancero.

Among the few poems by Francisco de Terrazas that have been available to us, there is an Epistle. The epistle is a genre that has been practiced "since the origins of the Mediterranean Civilization" and throughout the centuries its practice and its rhetoric have undergone changes, although its essence has remained immutable. Terrazas's Epistle embraces and violates this tradition. Starting from a motif that has its origins in troubadour poetry and Dolce Stil Novo, Terrazas shows a complete knowledge of the epistolary genre; the mastery of its rhetoric; the imitation of various Latin poems. Furthermore, novel elements are added; being the recurrence of a characteristic motif of the popular Hispanic lyrical poetry one of the most important. The article includes the transcription of the original poem written by Terrazas, which is analyzed through the revelation of both the classic sources and the new elements included by the Mexican poet.

KEY WORDS: Francisco de Terrazas, colonial poetry, epistle, classical tradition, romancero. 
Seguimos siendo hijos del siglo XIX y no acabamos de aceptar la literatura de otras edades si no es pasándola por filtros decimonónicos. Del romanticismo nos ha quedado en especial el mito de la originalidad, la vaga convicción de que la obra de arte es pura efusión del genio, disonancia y revelación estrictamente personal, tanto más digna de estima cuanto más lejos del común de los mortales, y desde luego del común de los artistas.

Juan F. Alcina y Francisco Rico

Los poemas de Francisco de Terrazas conservados en el ms. 506 ("Poesías de varios autores") de la Biblioteca Pública de Toledo, que fueron descubiertos por don Pedro Henríquez Ureña (Henríquez Ureña, passim) ${ }^{1}$ están encabezados por una Epístola de Fran ${ }^{c o}$ de Terrasas, que ocupa los folios 268r-271r del volumen. El título de la composición no parece ser del propio poeta (como no lo son, con evidencia, los del resto de los poemas de Terrazas que figuran en el manuscrito mencionado), sino del recopilador de las "poesías de varios autores" en él contenidas; pero el poema, escrito en tercetos encadenados, es, sin duda, una epístola.

Conviene señalar que el Cancionero en que aparece recogida esta Epístola, según señalan sus más autorizados editores, es anterior a Flores de varia poesía (1577), que contiene las únicas composiciones líricas conocidas de Terrazas antes del descubrimiento de Pedro Henríquez Ureña; ya que, aunque el primero incluye varios de los poetas presentes en el segundo,

...en éste ya se refleja un notable cambio generacional, pues están presentes nombres tan significativos del entorno hispalense en las décadas inmediatas como Juan de Mal Lara, Fernando de Herrera o Juan de la Cueva. Esto viene a confirmar que [el Cancionero sevillano] reúne poesía de una etapa algo anterior

\footnotetext{
Henríquez Ureña transcribe las cinco composiciones de Terrazas que contiene el manuscrito: la epístola que aquí examinamos y cuatro sonetos (I, "Soneto, del dicho", íncipit "Parte más principal desta alma vuestra"; II, "Soneto, del dicho", íncipit "Cuando la causa busco del efeto"; III, "Soneto a vna sangría, del dicho", íncipit "La mano que os dejó, de una sangría"; IV, "Soneto, del dicho", íncipit "La diosa que fue en Francia celebrada"). El manuscrito completo ha sido publicado recientemente (Cancionero sevillano); los poemas de Terrazas se transcriben en las págs. 258-260.
} 
[a las Flores], es decir, hacia 1550-1560, y debió copiarse... entre 1560 y 1570 (Cancionero sevillano) $)^{2}$.

La Epístola de Terrazas aparece también, sin atribución, en el Cancionero de poesías varias (ms. nº 617 de la Biblioteca Real de Madrid, ff. 296r-297v), ${ }^{3}$ que probablemente se terminó de compilar entre 1568 y 1571 . Entre la versión de este manuscrito y la del de Toledo hay algunas variantes que anotamos en la transcripción del texto (infra).

$$
* * *
$$

La epístola es un género de venerable antigüedad, tanto en su sentido de "carta o misiva que se escribe a alguien", cuanto, más sorprendentemente, en el de "composición poética en que el autor se dirige o finge dirigirse a una persona real o imaginaria”. Claudio Guillén, en un artículo imprescindible para la comprensión del género $(1986,101-127)$ cita diversos ejemplos de "esta imitación de la carta por la carta", practicada "desde los orígenes de la civilización mediterránea". La retórica del género epistolar aplicada a la epístola en prosa (si bien la contaminación entre ella y la epístola en verso es notoria) fue considerablemente desarrollada en la Edad Media (Murphy, passim $)^{4}$.

Ya Hugo de Bolonia, Rationes dictandi prosaice (h. 1119-1124) declara que hay dos tipos de género epistolar, el prosaico y el métrico: videlicet prosaicum, alterum quod vocatur metricum, y aunque solo trata del prosaico, establece que hay en ellos las siguientes partes: (salutatio), exordium, narratio, conclusio. Otros tratadistas de la época establecen cinco partes: I) salutatio: expresión de cortesía que conlleva un sentimiento amistoso, con independencia del rango social de las personas de que se trate. II) captatio benevolentiae: ordenación adecuada de las palabras para influir con eficacia en la mente del receptor. III) narratio: informe de la materia en discusión, de manera clara y ordenada; en la cual se puede distinguir narraciones sencillas (exposición

2 Como indican los editores de la obra (18) "La fecha de 1560 y la diferencia generacional que se percibe con respecto a Flores de baria poesía fueron señalados por" José Manuel Blecua (Blecua, passim).

Cito por la edición moderna, en que la epístola en cuestión aparece con el número de orden 429 (Cancionero de poesías varias 455-458).

V. esp. "Ars dictaminis: el arte epistolar" (202-274), algunas de cuyas noticias resumo en los dos párrafos siguientes. 
de un solo asunto) y complicadas (cuando abarca diversas materias), que pueden referirse al pasado, al presente o al futuro. Iv) petitio: parte dedicada a la petición de algo, que puede ser suplicatoria, didáctica, conminativa, exhortativa, incitativa, admonitoria, de consejo autorizado, reprobatoria o directa. v) conclusio: pasaje con que termina la carta y que puede resumir los temas tratados en la narración para que queden impresos en la memoria del destinatario.

La pervivencia de la dispositio general de la epístola hasta los Siglos de Oro españoles se hace patente en Luis Alfonso de Carballo, quien en 1602, en el Capítulo XXV de su Cisne de Apolo ("De las Epístolas o Cartas misivas"), anota que el orden que se puede seguir para escribirlas es:

El arbitrario como de ordinario suelen hazer los Poetas. Mas si algún modo y orden quieren guardar en algunas epístolas graues, diuidirá la carta en quatro partes, en Exordio, Proposición, Confirmación, y Fin. En el Exordio se procura ganar la voluntad de la persona a quien escriue. En la Proposición se propone lo que se pretende con la carta. En la Confirmación traeremos razones y causas para poder alcançar y conseguir lo que se pretende. Y en el Fin comprehender lo dicho en breue suma (Carballo II, 105-106).

$$
* * *
$$

Durante el Renacimiento, el género epistolar había vuelto su mirada hacia la tradición clásica, dando origen a multitud de textos (prosaicos, poéticos y teóricos) entre los cuales Claudio Guillén distingue siete clases (Guillén $1986)^{5}$. Todas las formas enumeradas por Claudio Guillén (acaso con la excepción de las agrupadas bajo el número 6) fueron cultivadas en la América virreinal si bien las conocidas hasta ahora (con la notoria excepción de las cartas vernáculas en prosa) no son numerosas.

En lo que dice relación con las "epístolas poéticas" en lengua vernácula conviene observar que en la época hay una evidente contaminación entre epístola y elegía, que puede ya percibirse en la literatura latina y que se ve favorecida, aparte de otras razones quizás más significativas, en cuanto en

5 Carta neolatina en prosa; carta vernácula en prosa; epístola neolatina en verso; epístola poética en diversas lenguas vernáculas; teoría de la carta; manuales prácticos de escribir cartas; cartas insertas dentro de otros géneros. 
español la epístola y la elegía en verso adoptaron preferentemente la forma métrica de tercetos endecasílabos encadenados en una serie cerrada por una cuarteta, según el esquema ABA BCB CDC... YZYZ (en italiano terza rima, terzina incatenata o terzina dantesca, denominación esta última debida a que se encuentra documentada por primera vez en la Divina Commedia) ${ }^{6}$.

$$
* * *
$$

La epístola y la elegía no fueron géneros muy frecuentados en los primeros tiempos de la América virreinal. El manuscrito de Flores de baria poesía (recopilado en 1577, como queda dicho) contiene doce composiciones tituladas "epístolas", todas ellas escritas en tercetos encadenados. Se cuentan además otros nueve poemas en tercetos, titulados "elegías". Ahora bien, de ese total de veintiuna composiciones, no hay ninguna atribuida a un autor del Nuevo Mundo.

Entre las manifestaciones de la epístola poética en la Nueva España, anteriores al siglo XVII, habría que incluir, además, la "Epístola al Licenciado Laurencio Sánchez de Obregón, Primer Corregidor de Méjico. Descríbese el asiento de la ciudad, el trato y costumbres de la tierra, y condiciones de los naturales della", que está incluida en la Rimas de Juan de la Cueva, nacido y muerto en España ( $c a .1543$ - ca. 1610), pero que residió en México entre 1574 y 1577, lugar en que escribió dicha epístola, aparentemente a poco de su llegada. También la "Epístola al insigne poeta Hernando de Herrera", de Eugenio de Salazar y Alarcón (¿1530-1602?), igualmente español, que vivió en México entre 1581 y 1598. Por otra parte, Gutierre de Cetina, poeta español que vivió en México, compuso numerosas epístolas y tradujo, antes de 1560, en tercetos, dos Heroidas de Ovidio: la de Penélope y la de Filis; además se le atribuye la de Dido a Eneas, pero ésta ha sido atribuida también a otros autores ${ }^{7}$.

$$
* * *
$$

6 Los tercetos encadenados endecasílabos fueron utilizados por primera vez en español por Boscán, en dos epístolas y en las poesías morales a las que llamó 'capítulos' (ya que, en época posterior al Dante, un poema en tercetos encadenados se denominó en italiano capitolo ternario, o simplemente capitolo o ternario). Claudio Guillén (1995, 34-39) comenta la impronta ovidiana en la mixtura entre elegía y epístola, respectivamente, en Tristia y Epistulce ex Ponto.

7 Sobre la epístola poética en la América Virreinal conviene consultar Sabat de Rivers 1992. 
Según sabemos, las cartas en verso, a partir del Renacimiento, suelen dividirse en dos grandes apartados (aunque la división permite algunos cruces y ambigüedades), ambos de origen latino: las epístolas de contenido moral y la carta de amores (que, si empleamos la nomenclatura pertinente de la lírica trovadoresca, puede adoptar la forma del singular escondich, o defensa de acusaciones; de mala cansó, en que se reniega del amor; o de simple salut d'amor).

Las epístolas morales, llamadas habitualmente horacianas (puesto que el modelo principal son las epístolas de Horacio), están dirigidas comúnmente a un amigo distante y expresan la intimidad del poeta a partir de valores éticos ligados a la filosofía moral de la época; la epístola horaciana está cercana al sermo o sátira, si bien esta última no está dirigida a un corresponsal en particular ${ }^{8}$. La epístola moral tuvo una considerable difusión en España, a partir de Garcilaso, durante toda la época áurea ${ }^{9}$.

También la epístola amorosa (más allá de sus antecedentes griegos) tiene modelos latinos; las Heroidas y las Epistulae ex Ponto de Ovidio son los principales, si bien Propercio y Tibulo cuentan también con numerosa descendencia.

Paul Veyne, en un libro memorable, ha estudiado las características fundamentales de la elegía erótica romana y establecido, de paso, las diferencias con su descendencia moderna, entre las cuales no es la única, pero tampoco la menor, el que mientras que en la segunda, en general, se suspira en vano por las amadas, "las heroínas de nuestro romanos no fueron tan crueles", ni eran damas nobles "a diferencia de su posteridad literaria" (Veyne 7).

También en el resto de las características de la elegía erótica romana (que el mismo Veyne resume así: "pastoral en ropa de ciudad, identificación del hombre con su oficio de poeta, juego de espejos y de mentís con el lector, pasión gratamente patética..., ostentación del libertinaje y el humorismo,... empleo bastante particular de la mitología" (Veyne 163)), hay diferencias más o menos acentuadas entre los modelos romanos y la elegía (o la epístola)

\footnotetext{
Cfr., por ejemplo, Mateo Rosas de Oquendo, Sátira de las cosas que pasan en el Pirú, año de 1598, incipit "Sepan cuantos esta carta", que ironiza el encabezamiento de otro tipo de cartas de la época.

Para un admirable resumen de la historia de la epístola moral en España y de sus características, a partir de Garcilaso, ver Juan F. Alcina y Francisco Rico, "Estudio preliminar", en Fernández de Andrada, esp.: XX-XXX.
} 
amorosa moderna. Pero ambas comparten una condición fundamental que no conviene perder de vista: son ficción, no "una tajada de la vida de nuestros poetas y de su supuesta amante".

$$
* * *
$$

La Epístola de Terrazas es una epístola poética en lengua vernácula, escrita en tercetos encadenados, acaso la primera debida a un autor nacido en América; es, además, una epístola amorosa de "efusión elegíaca". Su texto, que transcribo del manuscrito (corrigiendo algún error de copia, modernizando la ortografía, puntuando, acentuando y resolviendo las abreviaturas según el uso actual, salvo excepciones significativas), es el siguiente:

\section{Epístola de Francisco de Terrazas}

Pues siempre tan sin causa pretendiste ver acabar en tanto discontento esta vida cansada, dura y triste,

no puede ser que no te dé contento saber, después que en esta carta veas, el punto en que me tiene mi tormento.

Suplícote, señora, que la leas, pues ha de ser el fin de importunarte y no dudes que ves lo que deseas.

10 Muy bien puedes echar penas aparte y en verme haber venido a tal estado de ser más enojada asigurarte,

si acaso no te enojo en que he llegado al extremo del mal que me buscaste y en que he, con lo que quieres, acertado.

Alégrate, si nunca te alegraste, con mi memoria; pues la causa nueva te da cuantos efectos deseaste.

No pienses que te escribo porque mueva tu fiero corazón el dolor mío, que ya de su dureza ha hecho prueba, 
mas porque en ver mi carta yo confío (qué digo confiar, que desespero; aquí conoscerás que desvarío),

confío que en sabiendo como muero has de quedar, señora, tan contenta cuanto quejoso yo en no ser primero.

Quisiera, ya que quieres que consienta mi mal, saber la causa que te hace contino de mi muerte tan hambrienta.

Porque, si por ventura satisface alguna culpa mía aquesta pena, no diga que es por sólo que te place.

Mas es de razón cosa muy ajena buscar en tu querer yo más razón que saña y desamor que me condena.

¡Oh, cuántas veces vide en mi pasión tu libre voluntad, esquiva y dura, vestida con engaños de ocasión,

y viendo el fin de tanta desventura con falsas esperanzas sustentaba la vida ya deshecha de tristura!

¡Con cuántas conjeturas me engañaba (al menos procuraba de engañarme) en tanto que el dolor más aquejaba!

Mil veces, viendo ya desesperarme, dije: no puede ser que dure tanto, que no se acabe el mal con acabarme;

esto me causa ahora nuevo espanto, que no sé yo, muriendo, como vivo, si no es a pura fuerza de mi llanto.

Ni siento ya qué digo ni qué escribo, mas hago aquí testigo al alto cielo de tanta sinrazón como rescibo. y era creer que te contentarías con ver teñir mi sangre el duro suelo. 
Si es aquesto así, qué más porfías, qué más puedes querer, yo no lo siento, habiendo visto ya lo que querías:

mas muerte, ni dolor, ni sentimiento, jamás hartar pudieron tu deseo y menos acabar mi sufrimiento.

Yo sé, señora, cierto; yo lo creo, si vieses qué tal es mi triste vida en esta sepoltura en que me veo,

que ya que esa alma fiera, endurescida, a compasión ninguna se moviese, al menos mi pasión sería creída.

Estoy adonde, ya que me muriese, irá el alma bien aventurada si lo que aquí por ti, por Dios sufriese;

vivo una vida aquí desesperada, fuera del trato humano de la gente, 75 do solos muertos hacen su morada; querría el corazón del mal que siente dar cuenta, mas ni sabe ni podría: baste de ti, señora, estar ausente.

Baste que se me acuerde que solía, un tiempo venturoso, en solo verte ser otro del que ahora en alegría;

baste que tardará poco mi muerte, aunque a la vida dice el esperanza que no me quieres ver por no dolerte.

85 ¡Qué buen imaginar, qué confianza, que en ti quepa dolor de mi cuidado, si buscas en mi muerte tu venganza!

Huelga, pues llega ya aquel deseado tiempo en que desta triste sepoltura seré para la tierra trasladado;

adonde podrá ser que la tristura me deje, como en esta vida han hecho el bien, el alegría y la ventura. 
Un solo dolor rompe ahora el pecho, que es no te poder ver antes que muera.

Mas aún espero haber otro provecho,

que es que aunque tu saña no lo quiera, podrás pisar, pasando descuidada, la tierra do estará mi carne fiera. Y esto hará mi alma descansada ${ }^{10}$.

Se trata de una carta (ficticia, naturalmente) que un amante dirige a su desdeñosa amada comunicándole la proximidad de su muerte, de resultas del infinito dolor que le produce su amor no correspondido. Ese dolor extremo determina, quizás, que el orden de esta epístola sea más 'arbitrario' que el que "de ordinario suelen hazer los poetas". La salutatio (vv. 1-9) marca los rasgos generales que se van a desarrollar. El hablante se dirige a una dama (su 'señora', a quien tutea, según las convenciones del género), a la que ama desde hace tiempo (desde 'siempre', recalca el primer verso) sin haber sido jamás correspondido y a la cual se dirige ahora para comunicarle que al fin dejará de importunarla, lo que para ella será motivo de contento. El resto del exordio, que se extiende hasta el verso veintisiete, no hace sino explicitar las razones enunciadas: la carta no será un nuevo motivo de enojo para la amante desdeñosa (pues no es una nueva recuesta de amores, sino el anuncio de la muerte próxima del hablante ${ }^{11}$ ) y contiene una novedosa muestra de captatio

10 Las variantes entre la versión transcripta y la del Ms. 617 de la Biblioteca Real son las siguientes: v.2 'descontento'; v.3 'cansada, dura y triste'; v. 12 'asegurarte'; v. 15 'con lo que quieres acortado'; v.17 'con memoria, pues la caussa mía nueua'; v. 24 'conoçerás'; v. 3. 'no digo'; v.34 'mas es razón que cassa muy agena'; v. 37 'vi'; v. 41 'vanas esperanças'; v. 49 'agora'; v.54 'rreçiuo'; v. 67 'endureída’; v. 71 'yría’; v. 74 'tracto'; v. 81 'agora'. A partir del verso 93 hay, en el ms. 617 un problema no sé si del manuscrito mismo (lo que es lo más probable) o de la transcripción; copio los versos 93-96 del ms. 617: 'ques -no te poder ver antes que muera- / el bien, el alegría y la ventura. / Un solo dolor rrompe ahora el pecho, / ques no te poder ver antes que muera'. Desde el verso 96 de la versión transcripta (97 de los del ms. 617) los dos textos corren igual, pero el del ms. 617 termina en el 101, lo que delata su irregularidad.

11 De esta dolorosa circunstancia hay otros ejemplos en la poesía renacentista; $c f r$. por ejemplo el soneto de Diego Hurtado de Mendoza: "Hoy deja todo el bien un desdichado / a quien quejas ni llantos no han valido; / hoy parte quien tomara por partido / también de su vivir ser apartado. // Hoy es cuando mis ojos han trocado /el veros por un llanto dolorido; 
benevolentiae, que sirve a la vez de proposición (vv. 19-27). Lo que viene a continuación bien puede considerarse como una petitio preliminar, que antecede a la narratio (vv. 28-30). La narratio misma (vv. 31-96) se refiere a ese solo asunto, al pasado, presente y futuro de su amor desgraciado y a la "saña y desamor" que lo condenan y que, se imagina, no cesarán ni aun tras la muerte. La conclusio ocupa los últimos cinco versos de la epístola (vv. 96-100), de los cuales el primero tiene una entonación irónicamente macabra ("Mas aún pienso haber otro provecho").

$* * *$

El motivo principal del texto es la muerte por amor que, a partir de antecedentes clásicos, se extiende desde la poesía trovadoresca, el dolce stil novo y el petrarquismo hasta los Siglos de Oro, pasando por el romancero y llegando hasta la época moderna.

Los topoi principales de ese motivo en la Epístola de Terrazas incluyen, primero, el que el hablante se encuentre en un lugar "fuera del trato humano de la gente / do solos muertos hacen su morada" y, segundo, que imagine la propia muerte como remedio a sus males, topos este último que tiene, en el mexicano, un rasgo particular. El primero de los topoi mencionados, el del hablante que se retira a un lugar desierto para allí lamentarse de su sino (regularmente de su desventura amorosa), tiene una larga prosapia que puede remontarse, a lo menos en la tradición latina, hasta la segunda de las Bucólicas de Virgilio (que a su vez tiene ecos de los Idilios del poeta griego Teócrito, ca. 310 a. C.- ca. 260 a. C.):

El pastor Coridón al lindo Alexis -delicias de su dueño- idolatraba sin cosa que esperar. Sólo podía del hayedo sombroso a la espesura volver cada mañana, y allí solo a monte y selva, en impotentes ansias, repetir estas rústicas querellas:

// hoy vuestro desear será cumplido, / pues voy do he de morir desesperado. // Hoy parto y llego a la postrer jornada, / la cual deseo ya más que ninguna, / por verme en alguna hora descansada. // Y porque con mi muerte mi fortuna / os quite a vos de ser importunada / y a mí quite el vivir, que me importuna”. 
¿Con que no atiendes mi canto, Alexis?

¿No te apiadas, cruel? ¿Quieres que muera?'12

De los numerosos ejemplos del topos citaremos solo tres, en sentido inverso a su cronología. El más cercano a Terrazas es el de un soneto de Juan de la Cueva, el poeta sevillano que, junto con Gutierre de Cetina, tanta parte tuvo en Flores de baria poesía (Peña) ${ }^{13}$, aunque el soneto que sigue no figura en ese cancionero:

Sálgome d'entre el trato de la gente ${ }^{14}$, voyme por bosques solos y apartados a llorar mi desdicha y mis cuidados, ya que quien es la causa no los siente.

Y, como si ante mí fuera presente, le son todos por mí representados, los que presentes veo y los pasados, y los que a mi ocasión padezco ausente.

Tomo venganza en mí de mi osadía, que fue mayor que la de Prometeo, anqu'el castigo no cual merecía.

Muero viviendo, y vive mi deseo creciendo en más miserias cada día que males causó al mundo Epimeteo ${ }^{15}$.

12 Formosum pastor Corydon ardebat Alexin, / delicias domini, nec quid speraret habebat. / Tantum inter densas, umbrosa cacumina, fagos / adsidue veniebat. Ibi haec incondita solus / montibus et silvis studio iactabat inani. / "O crudelis Alexi, nihil mea carmina curas? / Nil nostri miserere? Mori me denique coges?”. Cito por la traducción de las 'Bucólicas...' de Aurelio Espinosa Pólit, en Virgilio, Obras completas.

13 Cetina ocupa también un lugar destacado entre los poetas recogidos en el Cancionero sevillano de Toledo: manuscrito 506, v. supra.

14 La coincidencia entre este verso y el de la Epistola de Terrazas "fuera del trato humano de la gente" podría indicar que el mexicano conoció el soneto de Juan de la Cueva; pero es justo indicar que se trata de un esquema de la expresión que tiene diversas antelaciones en la poesía española; por ejemplo, la de un soneto de Juan de Coloma recogido en el Cancionero general de obras nuevas nunca hasta aora impressa, 1554, cuyo primer cuarteto reza: "Por ásperos caminos desuiando, / triste me voy del trato de la gente / sospiros con mi voz ronca y doliente / en vano por el viento derramando" (que parece imitación del soneto petrarquesco que cito a continuación), o la de la Elegía $V$ de Fernando de Herrera, "La soledad abraço y no m'aplaze / el trato de la gente; en el olvido / el cuidado mil cosas muda y haze".

15 Obras de Ivan de la Cveva, BNM, R-13333, ff. 61v.-62. 
Este soneto parece ser imitación libre de otro, de Petrarca, que ocupa el lugar XXXV de Il Canzionere y dio ocasión a una serie de textos en las literaturas romances de los siglos XVI y XVII:

Solo e pensoso i più deserti campi

vo mesurando a passi tardi e lenti, e gli occhi porto per fuggire intenti ove vestigio uman l'arena stampi.

Altro schermo non trovo che mi scampi dal manifesto accorger de le genti; perché ne gli atti d'alegrezza spenti di fuor si legge com'io dentro avampi:

sì ch'io mi credo ornai che monti e piagge e fiumi e selve sappian di che tempre sia la mia vita, ch'è celata altrui.

Ma pur sì aspre vie né sì selvagge cercar non so ch'Amor non venga sempre ragionando con meco, et io co 1 lui ${ }^{16}$.

Lía Schwartz, en un artículo dedicado a rastrear la recepción que las elegías de Propercio (ca. 50 a. C.- ca.15 a. C.) tuvieron en el Renacimiento y, especialmente, en los poetas españoles del siglo XVI (Schwartz Lerner, passim); y señala que este soneto acaso esté inspirado por la elegía I, 18 del latino, especialmente por su primer verso, que "debe haberle parecido muy sugerente a Petrarca, porque expresaba una idea afín a la de su propia concepción del sujeto-amante". El poema de Propercio comienza con los siguientes versos:

En verdad solitario y discreto es este lugar para lamentos, y en el bosque vacío reina la brisa del Céfiro.

16 La versión de Garcés (soneto 28, ff. 17v.) traduce: “Con tardos pasos solo voy midiendo / pensativo los campos más desiertos, / y los ojos contino llevo abiertos, / por de humanos encuentros ir huyendo. // Que otro medio no veo, ni aun entiendo, / como pueda escapar de indicios ciertos, / porque en mis actos de alegría muertos / se lee fuera que voy dentro ardiendo: // De tal modo que pienso, antes lo digo / que no hay parte del mundo que no tenga / de mi triste vivir noticia cierta. // Y hora poblada sea, hora desierta, / ninguna entiendo que hay donde no venga / de mis cosas tratando Amor conmigo". El soneto de Petrarca no es citado, al hablar de Juan de la Cueva, por Fucilla. 
Aquí puedo expresar impunemente mis ocultos sufrimientos, si es que los peñascos desiertos pueden guardar secretos ${ }^{17}$.

y concluye:

Me he acostumbrado a soportar temeroso los mandatos todos de esa altiva, y a no lamentar con gritos de dolor sus desmanes. A cambio de esto lo que se me da son fuentes divinas y fría roca y duro descanso en inhabitados senderos; y todo lo que pueden contar mis quejas estoy obligado a decirlo solo a las canoras aves.

Pero seas como seas, que las selvas me hagan oír en eco 'Cintia' y que no estén privados de tu nombre los peñascos ${ }^{18}$.

En ese lugar solitario, el hablante se queja de la altanería de su amada y del desdén que ahora le muestra, desdén cuyos motivos no puede adivinar y le acongoja, aunque no lo lamente "con gritos de dolor".

$* * *$

Ahora bien, entre los posibles modelos mencionados y la Epístola de Terrazas hay, como habrá observado el lector, diferencias notorias. La primera es que mientras los hablantes de Virgilio, de la Cueva, Petrarca y Propercio parecen haberse retirado del mundo transitoriamente, para sufrir en silencio y en soledad el desamor de sus amantes, el remitente de la ficticia carta de Terrazas parece ser un 'desarraigado' esto es, como define la Academia, "Dicho de una persona: Que ha perdido los vínculos afectivos o culturales con su país, familia”. Observemos que Autoridades daba para 'desarraigar' en la segunda de las tres acepciones que recogía, a las cuales remitían 'desarraigado', la siguiente: "Metaphoricamente se toma en lo moral por extinguir y extirpar alguna cosa del todo", y la autorizaba, entre otras, con una cita de Fray Luis de León, "Nomb. De Christ, en el de Amado. Es tan grande este amor que

17 "Haec certe deserta loca et taciturna querenti, / et vacuum Zephyri possidet aura nemus. / hic licet occultos proferre impune dolores, / si modo sola queant saxa tenere fidem"; cito por Propercio, Elegías.

18 "omnia consuevi timidus perferre superbae / iussa neque arguto facta dolore queri. / pro quo divini fontes et frigida rupes / et datur inculto tramite dura quies; / et quodcumque meae possunt narrare querelae, / cogor ad argutas dicere solus aves. / Sed qualiscumque es, resonent mihi "Cynthia" silvae, / nec deserta tuo nomine saxa vacent" (Propercio). 
desarraiga de nosotros qualquiera otra afición". El hablante de la epístola de Terrazas es, pues, doblemente desarraigado: extraño en un mundo desolado, el amor por su amante desdeñosa le priva de cualquier otra afición.

A ello, acaso, podría atribuirse la segunda diferencia entre los textos citados y el de Terrazas. Mientras en su apartamiento temporal del mundo los hablantes de los primeros se encuentran en lo que podría denominarse un locus amœenus (hayedos umbrosos; bosques solos y apartados; monte y río, ribera y selva; fuentes divinas y canoras aves), en el mexicano no hay mención alguna de la naturaleza, aunque ésta se puede suponer hostil e inhabitada:

Estoy adonde, ya que me muriese, irá el alma bien aventurada si lo que aquí por ti, por Dios sufriese;

vivo una vida aquí desesperada, fuera del trato humano de la gente, do solos muertos hacen su morada (vv. 70-75).

Es justamente esa desesperación la que parece mayor en Terrazas que en sus posibles modelos y el propio hablante se encarga de expresar, con ambigüedad, el temple de ánimo que tiñe todo el texto: "Ni siento ya qué digo ni qué escribo" (v. 52). La oposición fundamental que se establece entre 'esperanza' y 'desesperación' es común en el género, y, en general el anthiteton (i.e., "la contraposición de dos res opuestas" que puede "expresarse lingüísticamente mediante palabras aisladas, grupos de palabras o frases enteras", Lausberg $\S 787)$ es un recurso presente en la poesía occidental desde la antigüedad clásica hasta nuestros días, si bien su uso se extendió notoriamente a partir de los poetas provenzales, de quienes lo tomó Petrarca que en Il Canzoniere hace de él un uso constante ${ }^{19}$. Pero ese lugar común (que da lugar, en la Epístola de Terrazas, a una serie de otras antítesis) tiene, también y sin embargo, una torsión especial en el mexicano, que potencia la desesperación y determina que lo escrito esté, desde sus inicios, marcado por la convicción de la muerte próxima y el convencimiento de que ella habrá de complacer a la cruel amante a que se dirige.

$$
* * *
$$
"Pace non trovo e non ho da far guerra"), está construido sobre una serie de antítesis. Sobre el uso del anthiteton en la poesía española de los Siglos de Oro, v. Mayoral 227-265. 
Imaginar la propia muerte como fin de los males de amor (el segundo de los topoi presentes en la Epístola de Terrazas), se encuentra en numerosísimos textos desde la antigüedad clásica hasta las literaturas modernas, con diversas variantes que van desde el pensamiento no realmente vivido, que el propio hablante desecha prontamente ("La vida huyo y al morir he miedo, / y al cabo de rüin sé que no muero, / y en esto yo de mi quexoso quedo", dice Boscán en una epístola famosa; Boscán 339-348), hasta el suicidio por amor, imaginado o realizado ${ }^{20}$.

A la constelación general de las variantes del topos podría agregarse otra, igualmente de origen clásico, que en apariencia es su contraria, pues pretende que las congojas del amor no terminan con la muerte. De sus abundantes ejemplos el más renombrado, sin duda, es el del soneto de Quevedo al que se conoce con el nombre mismo del tópico: Amor constante más allá de la muerte, de cuyo terceto final

su cuerpo dejará, no su cuidado

serán cenizas, mas tendrá sentido;

polvo serán, mas polvo enamorado.

Borges observó:

No pocas veces el punto de partida de Quevedo es un texto clásico. Así, la memorable línea (Musa, IV, 31):

Polvo serán, más polvo enamorado

es una recreación, o exaltación, de una de Propercio (Elegías, I, 19):

Ut meus oblito pulvis amore vacet (Borges 61).

La elegía de Propercio invocada por Borges imagina como más doloroso para el amante que la propia muerte, el que ella se produzca cuando su amor no sea ya correspondido, o dé ocasión a un dolor fingido. Rezan sus primeros versos:

No siento miedo ahora, Cintia mía, de los sombríos Manes y no me preocupan los hados debidos a la pira final; 
pero el que acaso mi entierro carezca de tu amor, éste es un temor más cruel que las mismas exequias ${ }^{21}$.

$\mathrm{Y}$, tras algunas referencias mitológicas, recalca:

Allí, sea yo lo que sea, siempre se me dirá imagen tuya; un gran amor traspasa incluso las riberas de la muerte ${ }^{22}$,

para concluir:

¡Ojalá puedas tú, viviendo, sentir todo esto en mis cenizas!, entonces para mí en ningún lugar sería amarga la muerte.

¡Cómo temo que a ti, Cintia, despreciando mi sepulcro, te arranque de mis restos, hostil a mí, Amor, y te obligue a secar a la fuerza tus deslizantes lágrimas!

Se doblega a amenazas asiduas una amante aunque sea fiel.

Por esto, mientras podamos, gocemos nosotros amándonos:

Con ninguna duración es bastante largo un amor ${ }^{23}$.

De suerte que en dos elegías correlativas de Propercio (I, 18 y I, 19, que forman parte de una trilogía dedicada a Cynthia, que concluye en I, 20) se encuentran los dos topoi principales del poema de Terrazas: el que el hablante se encuentre en un lugar "fuera del trato humano de la gente / do solos muertos hacen su morada" y el que imagine su propia muerte. Pero de ello no puede deducirse que el mexicano tuviese como modelo al poeta de Urbino (por más que este fuese ampliamente conocido en los Siglos de Oro españoles ${ }^{24}$ ), puesto que los dos tópicos se encuentran unidos en otros textos.

$$
* * *
$$

21 "Non ego nunc tristis vereor, mea Cynthia, Manis, / nec moror extremo debita fata rogo; / sed ne forte tuo careat mihi funus / amore, hic timor est ipsis durior exsequiis", Propercio 222-224, vv. 1-4.

22 "Illic quidquid ero, semper tua dicar imago: / traicit et fati litora magnus amor". Propercio 222-224, vv. 11-12.

23 "quae tu viva mea possis sentire favilla! / tum mihi non ullo mors sit amara loco. / quam vereor, ne te contempto, Cynthia, busto / abstrahat a nostro pulvere iniquus Amor, / cogat et invitam lacrimas siccare cadentis! / flectitur assiduis certa puella minis. / Quare, dum licet, inter nos laetemur amantes: / non satis est ullo tempore longus amor". Propercio 222-224, vv. 19-26.

$24 \quad$ Schwartz, indica las ediciones de Propercio que pueden haber leído los poetas españoles en el siglo XVI: "La editio princeps de las Elegías fue impresa anónimamente 
Entre ellos en uno famosísimo, que ha sido denominado "la più bella elegia ovidiana dell'esilio" (Argenio), esto es, la tercera del tercer libro de Tristium de Ovidio. Ovidio, por razones no del todo claras, fue relegado por Augusto, el año 8 de nuestra era, a Tomis, lugar periférico del Imperio Romano en el noreste de Europa, cerca de la desembocadura del Danubio en el Mar Negro, territorio habitado por getas y sármatas, gente bárbara a juicio del poeta.

Aunque en Roma la relegación no privaba de los derechos de ciudadano, no por ello dejaba de ser un destierro que Ovidio sintió (quizás exageradamente) en toda su crudeza. En ese destierro escribió las elegías de Tristium y Epistulae ex Ponto que documentan su desolación. El tercer libro de Tristium fue escrito en el año 10 (y es, por consiguiente, posterior a las elegías citadas de Propercio que datan del 28 a. C.) y está formado por catorce poemas; el que nos ocupa (III, 3) adopta la forma de una epístola a su esposa, en la que, tras una doliente salutatio, el poeta describe las aborrecibles circunstancias en que vive:

¿Qué ánimo piensas que tengo, postrado en una horrenda región entre los saurómatas y los getas? No soporto el cielo ni me acostumbro a esas aguas, y no sé de qué modo no me gusta la propia tierra. La casa no bastante apta, la comida aquí inadecuada para el enfermo, nadie, que alivie mi dolencia con el arte de Apolo, no hay ningún amigo que me consuele, ni que entretenga charlando conmigo el lento transcurrir del tiempo. Yazgo extenuado entre los pueblos y los lugares más remotos y ahora me viene en mi padecimiento todo lo que está lejos ${ }^{25}$,

en Venecia, en 1472 y en el mismo año, según Reynolds, apareció una edición conjunta de la poesía de Propercio, Catulo y Tibulo, de la que derivan otros incunabula del siglo XV. Como sabemos, las obras de Catulo, Tibulo y Propercio se difundieron principalmente en las ediciones conjuntas que fueron ofreciendo las prensas venecianas de Aldus Manutius desde las primeras décadas del siglo XVI....". Agreguemos que Maurer, nota 33, sugiere que "la pesadilla de Terrazas ([el soneto incipit ] 'Soñé que de una peña me arrojava...'), recuerda una elegía de Propercio (II: XXVI)".

$25 \quad$ "Quem mihi nunc animum dira regione iacenti / inter Sauromatas esse Getasque putes? / Nec caelum patior, nec aquis adsueuimus istis, / terraque nescio quo non placet ipsa modo. / Non domus apta satis, non hic cibus utilis aegro, / nullus, Apollinea qui leuet arte malum, / non qui soletur, non qui labentia tarde / tempora narrando fallat, amicus adest. / Lassus in extremis iaceo populisque locisque, / et 
y prevé que en esa tierra inhóspita tendrá lugar su cercana muerte, lejos de su patria y de su esposa, a quien extraña como a nada:

¡Por consiguiente moriré ya lejos en una costa desconocida y mi destino llegará a ser triste por el propio lugar; y mi cuerpo no languidecerá en el lecho acostumbrado ni habrá nadie que me llore de cuerpo presente; ni por las lágrimas de mi esposa cayendo en mi rostro se añadirá un poco de tiempo a mi vida; ni dejaré mi última voluntad, ni con la última llamada una mano amiga cerrará mis ojos desfallecientes; sino que sin funerales, sin las honras del sepulcro, una tierra bárbara cubrirá esta cabeza no llorada!26

Tras lo cual imagina el dolor que su muerte causará a su esposa e incluye lo siguientes versos:

Ahora, si puedes -pero no puedes, ¡oh la mejor de las esposas!-, alégrate de que con la muerte se me terminen tantas desgracias ${ }^{27}$,

curiosamente semejantes (aunque de signo inverso) a los versos 16-18 de la Epistola de Terrazas:

Alégrate, si nunca te alegraste, con mi memoria; pues la causa nueva te da cuantos efectos deseaste.

El poema de Ovidio concluye con el ruego de que sus restos sean trasladados a Roma y enterrados allí (fuera del recinto amurallado, pues todos los entierros estaban prohibidos en tal lugar), con un epitafio que él mismo indica:

subit adfecto nunc mihi, quicquid abest". Cito por la traducción de Eulogio Baeza Angulo de Ovidio 82-85.

26 "Iam procul ignotis igitur moriemur in oris, / et fient ipso tristia fata loco; / nec mea consueto languescent corpora lecto, / depositum nec me qui fleat, ullus erit; / nec dominae lacrimis in nostra cadentibus ora / accedent animae tempora parua meae; / nec mandata dabo, nec cum clamore supremo / labentes oculos condet amica manus; / sed sine funeribus caput hoc, sine honore sepulcri / indeploratum barbara terra teget!".

27 "Nunc, si forte potes (sed non potes, optima coniunx) / finitis gaude tot mihi morte malis". 
Sin embargo, procura que mis huesos sean guardados en una urnita: así, muerto, no seré ya un desterrado (nadie prohíbe esto: una hermana tebana, aunque lo vetaba el rey, dio sepultura a su hermano muerto) y mézclalos con hojas y polvo de amomo e inhúmalos en un suelo de las afueras de Roma; y para que el viajero de mirada apresurada los lea, graba en grandes caracteres sobre el mármol del túmulo estos versos: AQUí YAZGO YO, EL POETA NASÓN, CANTOR DE TIERNOS AMORES, QUe Perecí POR Mi Propio talento. Pero a ti, Caminante, QUien SEAS, SI AMASTE, NO TE PESE DECIR: ¡QUE LOS HUESOS DE NASÓN REPOSEN EN PAZ! Esto basta en el epitafio: pues mis libritos son para mí el mayor y más perdurable monumento, en los que yo confío, aunque me dañaron, que otorgarán a su autor fama e inmortalidad ${ }^{28 .}$

La epístola de Ovidio reúne los dos topoi de la de Terrazas, pero en el latino la previsión de la propia muerte nace no del amor no correspondido, como en el mexicano, sino del propio exilio. Por otra parte, el destinatario de la primera es identificado (la esposa del poeta) en tanto el de la segunda no. Y el mismo remitente es expresamente, en Ovidio, el propio autor, mientras en Terrazas el hablante es anónimo. Esas tres diferencias hacen que la epístola ovidiana pueda leerse como más verosímil que la que nos ocupa ${ }^{29}$. Creo, sin embargo, que Terrazas tuvo en mente (entre otros modelos posibles) Tristium III, 3, para la composición de su Epístola. No solo por el general tono de desesperación que tiñe una y otra, sino porque algunos lugares comunes y la dispositio general de ambas, cambiando lo que haya que cambiar, es extremadamente semejante y culmina en la conclusio de ambos poemas.

$* * *$

28 "Ossa tamen facito parua referantur in urna: / sic ego non etiam mortuus exul ero. / (non uetat hoc quisquam: fratrem Thebana peremptum / supposuit tumulo rege uetante soror) / atque ea cum foliis et amomi puluere misce, / inque suburbano condita pone solo; / quosque legat uersus oculo properante uiator, / grandibus in tituli marmore caede notis: / HIC EGO QVI IACEO TENERORVM LVSOR AMORVM / INGENIO PERII NASO POETA MEO; / AT TIBI QVI TRANSIS NE SIT GRAVE QVISQVIS AMASTI / DICERE NASONIS MOLLITER OSSA CVBENT / hoc satis in titulo est: etenim maiora libelli / et diuturna magis sunt monimenta mihi, / quos ego confido, quamuis nocuere, daturos / nomen et auctori tempora longa suo".

29 Por más que el exilio mismo de Ovidio haya sido puesto en duda (Fitton Brown) y que las circunstancias atroces de aquél parecen haber sido, en todo caso, exageradas por el poeta. 
Cierto es que, a primera vista, la conclusión de los dos textos parece muy diversa. Mientras en el poema de Ovidio se señala el epitafio que habrá de colocarse sobre sus restos (y aun el lugar en que estos deberán ser depositados), una vez cumplida su muerte, en el poema de Terrazas solo se indica que su desdeñosa amante podrá pisar "pasando descuidada, / la tierra do estará [su] carne fiera", lo que hace suponer que la tumba no estará ni identificada ni en lugar conocido. Estos detalles macabros nos permiten pensar que el hablante de la Epístola de Terrazas morirá por suicidio, lo que por otra parte está enunciado veladamente en los versos

Una cosa me daba algún consuelo y era creer que te contentarías con ver teñir mi sangre el duro suelo (vv. 55-58).

$* * *$

El suicidio por amor es un esquema del pensamiento y de la expresión abundante en la poesía clásica. Fernando Navarro Antolín (Navarro, passim) ha estudiado este motivo en los elegiacos, citando una abundante bibliografía e invocando una gran cantidad de ejemplos que se remontan a la obra de Homero y entre los que se incluyen varios de Ovidio y de Propercio. Navarro Antolín establece tres amplios grupos en los cuales pueden ordenarse los múltiples casos del motivo:

A) como testimonios de fides et amor... suicidios cometidos: a) bien para salvar a la persona amada; b) bien para acompañar o no sobrevivir a la persona amada en su muerte;

B) como remedia amoris acerbi... suicidios perpetrados por desesperación;

C) los que atañen al pudor et castitas... suicidios cometidos: a) bien para expiar una impiedad cometida; b) bien para lavar una deshonra recibida.

Y explica que la civilización romana fue sumamente tolerante con el suicidio, que las leyes no castigaban al suicida, que el suicidio era "incluso visto como el acto supremo de libertad, como un testimonio" de valor y de dignidad, y que la frecuencia de suicidios "registrados entre los siglos I a. C. y I d. C. dentro las clases dirigentes invita a pensar en una libido moriendi característica de la idiosincrasia romana" (Navarro, passim). 
En cambio, como se sabe, en la tradición católica (al menos desde el siglo VI con las prescripciones de San Gregorio de Tours sobre los cementerios y los rituales mortuorios), solo los bautizados podían ser enterrados en un camposanto, y aun habiendo recibido el primer sacramento, los herejes, los excomulgados, los criminales y los suicidas estaban excluidos de aquel beneficio $^{30}$. Esa tradición era la seguida en España en el siglo XVI y había sido trasplantada al Nuevo Mundo con la conquista ${ }^{31}$.

$\mathrm{Si}$, en verdad, la Epístola de Terrazas tiene parcialmente como modelo la de Ovidio, la elección de una muerte que lo excluirá de un entierro canónico (esto es, el suicidio, así sea como remedia amoris acerbi), puede nacer, bien de una mala intelección de los versos finales del poema del latino, bien de una premeditada variación patética de ellos. Sea como fuere, el hablante de Terrazas no aspira a que su cadáver sea inhumado en un lugar determinado, ni a un perdurable monumento que lo recuerde. Llevando el orgullo de su amor inextinguible a límites luciferinos, cree que su alma solo descansará en paz cuando su amante pise la tierra que cobije sus restos.

$$
* * *
$$

Corrijamos lo que acabo de escribir: el remitente de la Epistola de Terrazas pretende que su cadáver sea inhumado en un lugar anónimo, no canónico: quiero decir, fuera de las normas y preceptos generales, y fuera de los cánones eclesiásticos. Esto es, en un lugar no sagrado. No utilizo esa fórmula inocentemente. 'No me entierren en sagrado' es un motivo folclórico cuya presencia en el romancero hispánico se encuentra en multitud de textos de España, Portugal e Hispanoamérica, al menos desde el siglo XVI, y creo

30 Es más, si atendemos al Marqués de Santillana, no era propio de un caballero el suicidarse. Así se sigue del V de sus "Sonetos fechos al itálico modo", en el cual "el actor fabla en nombre del Infante Don Enrique, é muestra cómo se quexa por la muerte de la señora Infante, doña Catalina, su mujer; é diçe que non solamente al çielo é perturable gloria la quería conseguir, donde él se cuyda é ha por dicha ella yva, segund la vida é obra suyas, mas aun al infierno ó malino çentro, si por aventura dado le fuesse ferirse él mismo é darse á la muerte por golpe de fierro, ó en otra qualquiera manera"; el soneto (incipit "No solamente al templo divino") dice en el segundo cuarteto: "Mas al abismo é çentro malino/ Te seguiría, si fuesse otorgada/ Á caballero, por golpe ferrino,/ Cortar la tela por Cloto filada" (López de Mendoza).

31 Para ampliar estas modestas noticias puede consultarse, entre otros, a Rodríguez Álvarez. 
percibir un eco de él en la elegía de Terrazas. Según Diego Catalán, la más antigua documentación del texto es la del romance trovadoresco:

\begin{abstract}
"Si se está mi coraçón", incluido en un pliego suelto titulado Aqui se contienen doze Romances de amores muy sentidos...; [y] aunque el pliego sólo nos es conocido en una reedición tardía (hecha "En Granada en casa de Hugo de Mena. Año de mil y quinientos y setenta"), debió haber sido creado a principios del siglo XVI, dada la selección de textos poéticos que lo forman (Catalán 1997, 291-306).
\end{abstract}

Antes de esa reedición, el romance había aparecido en otras recopilaciones. En Martín Nucio, Cancionero de romances en que están recopilados la mayor parte de los romances castellanos que fasta agora se han compuests, Amberes, ¿1548?, que fue reimpreso en 1550 (hay edición moderna, Biblioteca Castro, 2004); en la tercera parte de la Silva de varios romances, publicada en Zaragoza en 1551, que reproduce muchos de los textos del Cancionero de romances, y que solo conozco por referencias (Silva 1551-1552) ${ }^{32}$; en la Flor de enamorats, compilada y editada por el librero-poeta valenciano Juan de Timoneda, Valencia, con toda probabilidad en 1556, pero hoy perdida $^{33}$; en la Silva de varios Romances agora nuevamente recopilados, impresa por Jaime Cortey en Barcelona, en 1561 (y en una reimpresión de esa obra, ca. 1570); y, finalmente, en la Flor de enamorados impresa en Barcelona por Claudi Bornat, 1562, que reproduce el libro de Timoneda (Flor de enamorados).

Sea como fuere, "entre las fórmulas discursivas extensas del romancero tradicional no hay otra tan universal y acomodaticia" (Catalán 1997, 291) como la constituida por los versos de aquel antiguo romance, cuyo texto Diego Catalán establece así:

32 Tomo la mayor parte de estas noticias de la reedición facsimilar de Silva 1953 y de Rodríguez-Moñino, que hace un exhaustivo estudio de las ediciones de la Silva.

33 Josep Romeu i Figueras descubrió un documento fechado el 27 de enero de 1556, por el cual se concedía privilegio al poeta y librero valenciano Joan de Timoneda para imprimir en exclusiva, por seis años, un libro llamado Flor d'enamorats, cuyo contenido (según el privilegio) coincide con el del libro de Bornat publicado en Barcelona en 1562 (v. infra); v. Josep Romeu i Figueras. Con esos antecedentes, Diego Catalán ("El romancero medieval") concluye que cree "evidente que Bornat lanzó en 1562 su edición porque ese año se acababa el privilegio de Timoneda y, por lo tanto, que la edición príncipe de la Flor de enamorados es de 1556 y valenciana (como, por otra parte, parecía indicar su propio contenido)". 


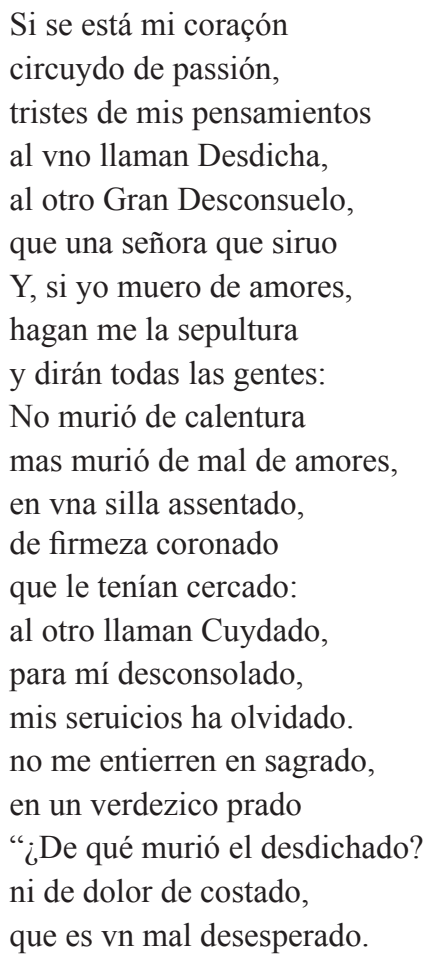

(Catalán 1997, 306)

El motivo fundamental de este romance, el que un hombre que va a morir pida ser enterrado en un prado, de suerte que la gente pueda saber que murió de mal de amores ${ }^{34}$ no es, exactamente el motivo de la conclusio de la Epístola de Terrazas. En ésta, el que va a morir ni siquiera desea que la gente sepa que está enterrado en donde lo esté (sin los letreros u otras señas identificadoras, que abundan en los romances que recogen el motivo), ni tampoco que se sepa que murió de mal de amores: como sabemos, su única aspiración es lograr que su alma descanse al fin cuando su amada, por descuido, pise ese lugar. 
Tal variación no desdice la posible raigambre popular del tópico, pues las contaminaciones y variaciones significativas son propias de la transmisión del motivo folclórico. De hecho, en las distintas versiones de romances que presentan el conocido como 'no me entierren en sagrado' hay una gran cantidad de ellas, que incluyen la causa de la muerte, el afectado por ésta, el lugar elegido para la sepultura, las señas que la han de identificar y el destinatario que habrá de reconocerlas, aparte de otros detalles ${ }^{35}$. Podría pensarse, con todo, que la conclusio de la Epístola de Terrazas difumina el motivo popular que la inspira para adecuarlo al tono general del poema.

Si los detalles faltan, el hablante del poema de Terrazas expresa, en cambio, su deseo de que la amada desdeñosa, aunque su saña no lo quiera, 'pise' "pasando descuidada, la tierra do estará [su] carne fiera". Curiosamente, varios de los romances que contienen la fórmula "no me entierren en sagrado", agregan una circunstancia significativa: "[entiérrenme en prado verde]/ donde me pise el ganado", con la variante "donde no pise el ganado" (y hasta, excepcionalmente, "donde pisen mis soldados"), que alternan con "donde pace [o 'pasta' o 'pasture'] mi [o 'el'] ganado", o "donde no pace [o 'pasta', o 'pazca', o 'pazga'] el ganado" y también "donde no pase ganado"; circunstancias que en algunos ejemplos conviven: "pa que me pise la gente / y me pazcan los ganados", y también "donde me pisen las damas / y me pazcan los ganados", o "donde me pisen las damas / y paseen los ganados" hay también otras numerosas variantes: "donde me trille el ganado", "donde transite el ganado", y alguna curiosa, como "ponedme en un verde campo / donde paceré a mi agrado", etcétera ${ }^{37}$; explicables, naturalmente, por la

35 Así, el que muere puede hacerlo por mal de amores o por otras causas (por ejemplo, por la cornada de un toro bravo); puede ser un pastor, un soldado o desempeñar otro oficio; puede elegir un lugar determinado o no para que se le entierre; pretender que ese lugar sea identificado por un letrero o por otras señas (dejando sus cabellos afuera; dejando sus armas sobre la sepultura; o, como en la leyenda de Gustavo Adolfo Bécquer, "La promesa", dejando una mano fuera de la tumba, etc.), para que lo reconozca su amada, o su madre, o simplemente "todas las gentes". Oscar Hahn, poeta chileno contemporáneo, en su Flor de enamorados (Hahn), que contiene "Transcripciones y recreaciones a partir del cancionero anónimo medieval 'Flor de enamorados', impreso en Barcelona por la casa Claudi Bornat, en año 1562", incluye una recreación del romance citado.

36 Observemos, marginalmente, que el hablante de la epístola de Terrazas imagina que su dama 'pasa' por, y 'pisa' su ignota sepultura.

37 Muchos de los romances que contienen los ejemplos enumerados pueden consultarse en Goldberg's. 
trasmisión oral de los romances. De todas, sin embargo, y aunque no estoy en condiciones de establecer el stemma de ese rasgo, la más abundante parece ser la que utilizó, ya en la segunda mitad del siglo XIX, el poeta argentino Rafael Obligado en su Santos Vega:

\begin{abstract}
Si jamás independiente veo el cielo en que he cantado, no me entierren en sagrado, donde una cruz me recuerde; entiérrenme en campo verde, donde me pise el ganado.
\end{abstract}

$$
* * *
$$

No podemos asegurar que Terrazas conociera algún romance de los que incluyen la fórmula 'no me entierren en sagrado'; y, si así fue, si lo conoció por alguna de las versiones impresas de los romances que la contienen (lo que es posible, dada la notable difusión del género en América en el siglo $\mathrm{XVI}^{38}$ ), o por la difusión oral de alguno de ellos, que, por cierto, existen también en el folclore mexicano.

La irrupción de un motivo popular en un género como la epístola (y en una forma métrica, los tercetos, generalmente aristocrática) justifica las últimas disquisiciones de estas ya excesivas páginas, en cuanto añade un registro más al ya amplio registro de la poesía del primer poeta novohispano. Desarrollar ese extremo excedería, en cambio, los límites de mis saberes y los de la paciencia del amable lector.

38 "Las lecturas del conquistador y de sus descendientes también comprendían otras formas de poesía. Los romances - tan cercanos al corazón del pueblo español-influyeron al igual que los libros de caballerías en la conquista, y pasaron como una hermosa herencia a las generaciones sucesivas en el Nuevo Mundo. En casi todas las listas de libros, parte de los envíos marítimos, figuran 'Romanceros' - o sea colecciones de romances-, y con frecuencia son los únicos ejemplares de literatura de ficción que se despachan junto a los áridos materiales de lectura que se consignan a nombre de algún docto eclesiástico" (Leonard 111 et passim); Leonard señala también el éxito de las compilaciones de Juan de Timoneda en la América virreinal, aunque no se refiere a los romanceros del valenciano. 


\section{BIBLIOGRAFÍA}

Argenio, R. "La più bella elegia ovidiana dell'esilio". Rivista di studi classici 7 (1959): 145-151.

Blecua, José Manuel. "Un cancionerillo casi burlesco". Homenajes y otras labores. Zaragoza: Institución Fernando el Católico, 1990. 163-171. [El artículo de Blecua había sido publicado originalmente en Homenaje a Agapito Rey. Bloomington, Indiana, 1980. 221-248].

Borges, Jorge Luis. “Quevedo”, Otras inquisiciones. Buenos Aires: Emecé, 1960, 61 (1 $1^{\mathrm{a}}$ ed., Buenos Aires: Sur, 1952, 160 págs.).

Boscán, Juan. Obra completa. Edición de Carlos Clavería. Madrid: Cátedra, 1999; la "Epístola" en 339-348; vv. 175-177.

Brown, Fitton. "The unreality of Ovid's Tomitan exile". Liverpool Classical Monthly 10 (1985): 19-22.

Cancionero sevillano de Toledo: manuscrito 506 (fondo Borbón-Lorenzana). Biblioteca de Castilla-La Mancha. Edición de José J. Labrador Herraiz, Ralph A. Di Franco, Juan Montero; prólogo de Begoña López Bueno. Sevilla: Secretariado de Publicaciones, Universidad de Sevilla, 2006, 636 págs.

Cancionero de poesías varias, manuscrito $n^{\circ} 617$ de la Biblioteca Real de Madrid. Ed. de J. Labrador, C. A. Zorita, R. A. Di Franco. Madrid: Visor, 1994, 667 págs.

Carballo, Luis Alfonso de. Cisne de Apolo. Edición de Alberto Porqueras Mayo. Madrid: Consejo Superior de Investigaciones Científicas, Instituto Miguel de Cervantes, 1958, 2 vols.

Catalán, Diego. "El romancero medieval". El comentario de textos 4, La poesía medieval. Castalia, 1983. 451-489.

Arte poética del romancero oral. Parte primera. Los textos abiertos de creación colectiva. Madrid: Siglo XXI de España, 1997, 365 págs.

Fernández de Andrada, Andrés. Epistola moral a Fabio y otros escritos. Barcelona: Crítica. 58.

Flor de enamorados. Cancionero llamado flor de enamorados, sacado de diversos auctores, agora nuevamente por mui linda orden copilado. Barcelona: Claudi Bornat, 1562. [Hay edición moderna: Cancionero llamado flor de enamorados (Barcelona 1562). Reimpreso por vez primera del ejemplar único, con un estudio preliminar de Antonio Rodríguez Moñino y Daniel Devoto. Valencia: Castalia, 1954].

Flores de baria poesía. Recoxida de barios poetas españoles. Divídise en cinco libros, como se declara en la tabla que inmediatamente va aquí scripta. Recopilóse en la ciudad de México, Anno del nascimiento de NRO salvador IHUchristo de 1577 Annos, ms. 2973 de la BN, Madrid. [Hay edición moderna: "Flores de baria poesía", prólogo, edición crítica e índices de Margarita Peña. México: UNAM, 1980].

Fucilla, Joseph G. "Estudios sobre el petrarquismo en España". Revista de Filología Española, Anejo LXXII. Madrid, 1960, 2 vols.

Garcés, Henrique. Los sonetos y canciones del poeta Francisco Petrarcha. Madrid: Guillermo Droy, 1591.

Goldberg’s, Harriet. Proyecto sobre el romancero pan-hispánico. http://depts.washington. edu/hisprom/espanol/. 
Guillén, Claudio. "Para el estudio de la carta en el Renacimiento". La epístola, V Encuentro Internacional sobre Poesía del Siglo de Oro. Ed. dirigida por Begoña López Bueno. Universidad de Sevilla, 2000, 458 págs.101-127. [El artículo había sido publicado anteriormente en inglés: "Notes Toward the Study of the Renaissance Letter", in Barbara K. Lewasky (ed.), Renaissance Genres. Cambridge: Mass., Harvard U.P, 1986. 70-101].

El sol de los desterrados. Literatura y exilio. Barcelona: Sirmio, Quaderns Crema, Biblioteca General, 1995. [El ensayo fue incluido después en Claudio Guillén.Múltiples moradas. Ensayos de Literatura Comparada. Barcelona: Tusquets, 1998].

Hahn, Oscar. Flor de enamorados. Santiago de Chile: LOM, 2a ed. corregida, 1997 (1ª , 1987).

Henríquez Ureña, Pedro. "Nuevas poesías atribuidas a Terrazas". Revista de Filología Española V (1918): 49-56.

Lausberg, Heinrich. Manual de retórica literaria. Fundamentos de una ciencia de la literatura. Versión española de José Pérez Riesco. Madrid: Gredos, 1967, 3 vols.

Leonard, Irving A. Los libros del conquistador. México: FCE, 1953 (1 $1^{\text {a }}$ ed. en inglés, 1949).

López de Mendoza, Íñigo. Obras de don Íñigo López de Mendoza; Marqués de Santillana, ahora por primera vez compiladas de los códices originales, é ilustradas con la vida del autor, notas y comentarios, por José Amador de los Ríos. Madrid, 1832.

Maurer, Christopher. “'Soñé que te... ¿Dirélo?'. El soneto del sueño erótico en los siglos XVI y XVII". Edad de Oro, vol. 9 (1990): 149-167.

Mayoral, José Antonio. Estructuras retóricas en el discurso poético de los siglos XVI y XVII, Valencia: Tirant lo Blanch, 2002, 302 págs.; "VIII. Estructuras antitéticas". 227-265.

Murphy, James J. La retórica en la Edad Media. Historia de la retórica desde San Agustín hasta el Renacimiento. México: FCE, 1986, 407 págs. [1 $1^{\text {a }}$ ed. en inglés, Rhetoric in the Middle Age. A History of Rhetorical Theory from St. Augustine to the Renaissance, 1974].

Navarro Antolín, Fernando. "El suicidio como motivo literario en los elegiacos". Emerita, fascículo $1^{\circ}$, tomo LXV, 1997.

Ovidio Nasón, Publio. Tristezas. Introducción, edición crítica, traducción y notas de Eulogio Baeza Angulo. Madrid: Consejo Superior de Investigaciones Científicas, 2005.

Peña, Margarita. "Juan de la Cueva, poeta del cancionero Flores de baria poesía". Actas del Séptimo Congreso de la Asociación Internacional de Hispanistas. Venecia, 25-30 de agosto de 1980, Giuseppe Bellini, ed. Roma: Bulzoni, 1982, 2. vols. 799-805.

Propercio. Elegías. Edición bilingüe de Francisco Moya y Antonio Ruiz de Elvira. Madrid: Cátedra, Letras Universales, 2001. 218-222.

Rodríguez Álvarez, María de los Ángeles. Usos y costumbres funerarias en la Nueva España. Zamora, Michoacán, México: El Colegio de Michoacán / El Colegio Mexiquense, 2001, 317 págs.

Rodríguez-Moñino, Antonio. La Silva de Romances de Barcelona, 1561. Contribución al estudio bibliográfico del romancero español en el siglo XVI. Universidad de Salamanca: 1969, 611 págs.

Romeu i Figueras, Josep. Joan de Timoneda i la 'Flor de Enamorados', Cançoner bilingüe: Un estudi i una aportació bibliogràfica. Barcelona: Reial Acadèmia de Bones Lletres, C.S.I.C., 1972, 108 págs. 
Rosas de Oquendo, Mateo. Sátira hecha por Mateo Rosas de Oquendo a las cosas que pasan en el Pirú, año de 1598. Estudio y ed. crítica de Pedro Lasarte. Madison: Hispanic Seminary of Medieval Studies, 1990.

Sabat de Rivers, Georgina. "Balbuena: géneros poéticos y la epístola épica a Isabel de Tobar". Estudios de literatura Hispanoamericana. Barcelona: PPU, 1992. 49-81.

"La epístola de Amarilis y su amor por Lope: ver, oír". Estudios de literatura Hispanoamericana. Barcelona: PPU, 1992. 137-155.

Schwartz Lerner, Lía. "Las elegías de Propercio y sus lectores áureos”. Edad de oro. Vol. 24 (2005): 323-350.

Silva. Silva de varios romances (Barcelona, 1561). Por primera vez reimpresa del único ejemplar conocido. Con un estudio preliminar de Antonio Rodríguez-Moñino. Valencia: Castalia, 1953.

Silva. 1551-1552. Tercera parte de la Silua de varios Romances. Lleua la misma orden que las otras. Impressa en Çaragoça por Steuan G. de Nagera, M.D.L.I.; La Silva ... recopilada por Esteban de Nájera tiene tres volúmenes (I, 1550; II, 1550; III, 1551).

Thompson, Stith. Motif-Index of Folk-Literature: A Classification of Narrative Elements in Folk Tales, Ballads, Myths, Fables, Medieval Romances, Exempla, Fabliaux, Jest Books and Local Legends. Bloomington: Indiana University Press, 6 vols., 1955-1958 (primera edición, 1932).

Veyne, Paul. La elegía erótica romana. El amor, la poesía y el Occidente. Traducción de Juan José Utrilla. México: Fondo de Cultura Económica, 1991 (1ª ed. en francés, 1983), 257 págs.

Virgilio Marón, Publio. Obras completas [traducción de 'Bucólicas...' Aurelio Espinosa Pólit]. Madrid: Cátedra, Biblioteca Áurea, 2003, 1403 págs. 